\title{
CIDADE, INFÂNCIA E ESCOLARIZAÇÃO: UM ENSAIO ANALÍTICO
}

CITY, CHILDHOOD AND SCHOOLING: AN ANALYTICAL ESSAY

CIUDAD, INFANCIA Y ESCOLARIZACIÓN: UN ENSAYO ANALÍTICO

\author{
Rodrigo Manoel Dias da Silva ${ }^{1}$ \\ Denise Madeira de Castro e Silva²
}

\begin{abstract}
${ }^{1}$ Doutor em Ciências Sociais pela UNISINOS. Docente do Programa de Pós-Graduação em Educação da Universidade do Rio dos Sinos (UNISINOS), São Leopoldo, RS, Brasil.

${ }^{2}$ Doutoranda em Educação pelo Programa de Pós-Graduação em Educação da Universidade do Rio dos Sinos (UNISINOS), São Leopoldo, RS, Brasil.
\end{abstract}

Resumo: $O$ presente artigo visa discutir a constituição das cidades nos projetos da modernidade e, mediante revisão de aportes dos campos da História e da Sociologia da Educação, problematizar sua pretensa competência educadora aludida em programas contemporâneos de indução de educação em tempo integral. Por meio de uma revisão teórica, buscou-se articular os conceitos de infância, escolarização, cidade e cidadania com vistas à delimitação das relações das crianças com os espaços urbanos, predominantemente supervisionadas pelos adultos.

Palavras-chave: Cidade; Infância; Escolarização.

Abstract: This paper discusses the constitution of cities in the today's urban planning, and by drawing on History and Sociology of Education works, investigates its supposed educational competence, as alluded to in contemporary full-time education induction programs. Through a theoretical review, it seeks discusses the concepts of childhood, education, city/town, and citizenship, aimed at defining the relationship of children with urban spaces, particularly those supervised by adults.

Keywords: City; Childhood; Schooling.

Resumen: El presente artículo pretende discutir la constitución de ciudades en los proyectos de modernidad y, las contribuciones de campos de la Historia y la Sociología de la Educación, problematizar su pretendida competencia educadora aludida en programas contemporáneos de inducción de educación en tiempo integral. Por medio de una revisión teórica, se buscó articular los conceptos de infancia, escolarización, ciudad y ciudadanía para delimitar las relaciones de los niños bajo la supervisión de los adultos con los espacios urbanos.

Palabras clave: Ciudad; Infancia; Escolarización. 
Francesco Tonucci, pedagogo e desenhista italiano, utilizando-se do pseudônimo Frato, produz uma série de quadrinhos irreverentes e críticos que evidenciam contestações ao modelo de escola tradicional vigente. Na historieta Os passeios instrutivos, sua verve analítica põe em relevo seu pensamento sobre a escola. Conforme a narrativa, a professora, ao convidar os alunos para passear, diz: "Crianças, hoje vamos passear! Sairemos para ver o bairro! Em frente, em fila de dois Deem-se as mãos... Não se distraiam... Não desçam da calçada... E agora vamos voltar para a aula. Cada um desenhe o que mais o impressionou" (TONUCCI, 2003, p.91). A experiência escolar retratada pode ser facilmente encontrada nas recordações de muitos estudantes de diferentes faixas etárias, vivenciadas em cidades e escolas de contextos diversos.

Semelhantes atividades explicitam um descompasso entre o espaço escolar e os espaços sociais que a circundam, caso da cidade. Como pensar as relações entre educação escolar e cidades contemporâneas? Como investigar as implicações entre os espaços escolares e os espaços da cidade? Esse pedagogo, ao assumir tais interpelações, levou a cabo a iniciativa Cidade das Crianças $^{1}$, que pretende considerar no planejamento urbano a presença dos pequenos nos espaços públicos, estratégia que foi consolidada nas cidades de Rosário (Argentina) e Pontevedra (Espanha). Em recente entrevista (TONUCCI, 2016), demarcou seu posicionamento, afirmando não querer uma cidade infantil, pequena, mas uma cidade para todos. Desse modo, a cidade deveria possibilitar a participação de todos os cidadãos no seu planejamento e condições de interação em seus diferentes espaços públicos. A obra de Tonucci oferece boas metáforas para se refletir sobre a presença das crianças nos espaços urbanos.

As pautas pedagógicas da atual agenda das políticas educacionais brasileiras evidenciam a crescente preocupação com a distribuição dos tempos e dos espaços escolares. Nesse sentido, a expansão da obrigatoriedade escolar e a consequente ampliação da jornada em tempo integral compõem metas específicas do vigente Plano Nacional de Educação (PNE2014/2024), impelindo desdobramentos próprios no exercício da organização curricular das escolas. A ampliação do tempo escolar em horas de permanência em busca do chamado turno integral ou da educação em tempo integral foi o mote do Programa Mais Educação (PME)². A base teórico-metodológica do PME foi alicerçada no conceito de Cidade Educadoraz, que, nas palavras de Moll (2012), parece ser pertinente, porque converte o território urbano em território intencionalmente educador: "baixar os muros da escola é colocá-la em diálogo com o que está em seu entorno em termos de políticas públicas, equipamentos públicos, atores sociais, saberes e práticas culturais" (p.142).

Os estudos acerca dos tempos e dos espaços escolares problematizam o propagado discurso da qualidade em educação, apontado nos documentos oficiais como a centralidade da justificativa para programas como o Mais Educação, considerado indutor de educação em tempo integral. Em pesquisa realizada por Algebaile e Rissato (2015), ao analisar as atuais políticas de escolarização em curso no Brasil, fica patente a necessidade da compreensão das novas formas e sentidos da diversificação da oferta escolar. Na visão dessas autoras, há uma universalização da escolarização sem a universalização das escolas. Cavaliere (2014), por sua 
vez, analisa a educação em tempo integral no Brasil como um dispositivo compensatório, ofertada a determinados grupos de alunos, assumindo um caráter provisório e instável. Ao examinar a ampliação da jornada escolar, Coelho (2014) destaca a situação de precariedade da implantação de programas, sem que as mínimas condições objetivas de trabalho sejam garantidas. Ainda nos idos dos anos oitenta, Santos e Vogel (1985), ao realizarem um estudo antropológico no bairro Catumbi, na cidade do Rio de Janeiro, argumentavam que, pelo intermédio da experimentação da vida pública, a criança poderá desenvolver noções de cidadania e civilidade de maneira mais intensa. Ainda que assumam objetivos sociais específicos e, por vezes, contraditórios, os projetos educativos que visam à organização da ampliação dos tempos escolares contam com os espaços das cidades como promotores de educação e cidadania.

Assim sendo, almeja-se, neste ensaio analítico, discutir a constituição das cidades nos projetos da modernidade e, mediante revisão de aportes dos campos da História e da Sociologia da Educação, problematizar sua pretensa competência educadora. Tal análise incide sobre a tendência contemporânea em definir a cidade como espaço político de aprendizagens, mediante estratégias que assumam diversas designações, com destaque para "cidades educadoras", "territórios educativos", "bairro-escola", dentre outras.

Para a consecução dessa proposta, esse artigo foi organizado em duas seções principais. $\mathrm{Na}$ primeira, a partir de uma revisão teórica, realizou-se uma contextualização da formação da escola e dos desdobramentos da construção histórica do conceito e da situação da custódia infantil no cenário da modernidade, cujo desenvolvimento das cidades integrou a edificação de um conjunto de saberes propícios à produção de um modo de vida. Na segunda, buscouse articular algumas concepções de cidadania e infância e sua configuração política no planejamento das cidades, bem como refletir sobre as possibilidades da efetivação de uma cidade educadora para as crianças.

\section{InfÂNCIA, Modernidade E Escolarização}

Nessa seção textual, a discussão mobilizará os conceitos de infância, modernidade e escolarização, buscando alinhá-los aos modos pelos quais desenvolveram-se as cidades contemporâneas. Verificar-se-ão, pois, os múltiplos e contraditórios objetivos que compuseram os projetos das formações urbanas, da higienização das classes populares aos delineamentos do trabalho assalariado, da melhoria das moradias aos "perigosos" à construção da nação. Os processos de escolarização foram fundamentais à efetivação desses intentos.

A primeira questão da presente abordagem corresponde aos termos com os quais se faz possível se definir a modernidade. Ao se reconhecerem as interfaces entre infância, modernidade e escolarização, vislumbra-se o entendimento de que a modernidade foi configurada a partir de múltiplos processos e dimensões. Há, portanto, lógicas de modernidade e não, necessariamente, a definição de um conceito. Tais lógicas podem ser expressas em três acontecimentos: "a extensão dos saberes elementares para toda a população, a produção de 
saberes racionais para interpretar, conhecer e intervir na sociedade e a difusão e universalização de formas específicas de tratamento da criança em distinção ao mundo adulto" (VEIGA, 2004, p.37).

Preliminarmente se pode interpretar, a partir do pensamento de Veiga (2004), que ao projeto da modernidade importava a propalação de saberes para o povo, visando à produção do homem civilizado por meio de uma instituição, especificamente a escola; a diferenciação entre os mundos da criança e do adulto e a criação de formas de intervenção nas cidades que operassem no sentido de colaborar para a constituição da nação. A incumbência de tornar o homem civilizado era extensiva à produção da criança civilizada. Passar-se-á a apresentar alguns contornos da construção desse processo sem esgotar a complexidade do tema.

A instituição escolar, tal qual se conhece hoje, é originária da modernidade, produzida a partir de um projeto político de controle da sociedade que visava à expansão em larga escala, sobretudo para as populações mais pobres. Objetivava tornar, por meio de práticas pedagógicas escolarizantes, o homem civilizado. De acordo com Veiga (2002, p. 97):

[...] A associação dos saberes pedagógicos produzidos a partir do século XVI às técnicas de controle social, em direção à produção do dispositivo escolarização, somente se tornaram possíveis quando o Estado monopolizou tais técnicas e saberes, no momento em que se tornou definitivamente necessário para o programa civilizador a incorporação dos pobres na sociedade civilizada.

Os estudos de Elias (1994), ao perscrutar como a humanidade se tornou educada e passou a tratar-se com boas maneiras, sem uma preocupação a priori com os problemas educacionais, possibilitaram várias reflexões e desdobramentos acerca da formação humana e da Pedagogia. Ao analisar as ideias desse autor, Veiga (2002, p.94) sugere que o processo de civilização é: "[...] como uma dinâmica que pressupõe alterações nas relações de poder e controle dos indivíduos, alterando as relações de interdependência e possibilitando a consolidação dos controles estatais". A escolarização permitiu a continuidade do processo de civilização com o domínio dos saberes e das técnicas de controle social pelo Estado. A infância passa a ser protegida pelo Estado, pela política e vista com um investimento social importante para o futuro das nações.

Nesse sentido, ao longo dos séculos XVI e XVIII, inicia-se um longo processo de mudanças nos hábitos e nos comportamentos, circunstância em que a escola assumiu posição basilar. As classes médias e altas já vinham sendo escolarizadas e as classes pobres passaram a ser vistas como potencialmente perigosas aos interesses da nação. Veiga afirma ainda que "a universalização ampliou para toda a população os modelos de autocoerção, o domínio das emoções, os sensos de vergonha e pudor, [...] ao inventar a educação escolarizada como categoria da atividade social" (2002, p.98).

Rui Canário, por sua vez, observa que a construção histórica da escola ocorre na transição das sociedades do Antigo Regime para as modernas sociedades industriais. Pressupõe a invenção da infância, e a relação pedagógica estabelecida começa a exigir um lugar próprio à socialização - a escola (CANÁRIO, 2008). Ainda de acordo com esse autor, 
O nascimento histórico, a consolidação e o desenvolvimento dos modernos sistemas escolares situam-se num contexto que é indissociável da dupla revolução (liberal e industrial) que marcou o final do século XVIII. Durante um largo período que, cronologicamente, podemos situar entre a Revolução Francesa e o fim da Primeira Grande Guerra, a escola viveu o que, hoje, podemos retrospectivamente considerar uma "idade de ouro", que coincide com o apogeu do capitalismo liberal e que permanece no imaginário colectivo com um referente a confrontar com os "males" da escola actual. (CANÁRIO, 2008, p.74).

A ideia de invenção ou construção social da infância cunhada por Ariès (1981) baseou-se em evidências da cisão entre o mundo dos adultos e o das crianças. A institucionalização dessas últimas por meio da criação de escolas públicas permitiu ao projeto da modernidade que os adultos se dedicassem ao trabalho. De acordo com Sarmento (2005, p. 367), o "sentimento" da infância "[...] desenvolveu uma consciência de alteridade das crianças em relação aos adultos, que é decisiva para essa construção histórica, com um contínuo, dinâmico e distinto (em face da Antiguidade) processo de desenvolvimento desde o dealbar da modernidade".

Entre os séculos XVI e XVIII, percebe-se um incremento dos saberes pedagógicos resultando no desenvolvimento de pedagogias como a Ratio Studiorum e a pedagogia Lassalista. A escola de massas ainda não era uma realidade, o professor e seus saberes não estavam sob o controle do Estado, mas entre as ordens religiosas ou entre os leigos. A partir do século XIX, percebe-se a preocupação da promoção da inclusão de todos no processo de civilização e o ideal pansófico de ensinar tudo a todos começa a se configurar (NARODOWSKI, 1999). Nesse sentido, a escola desempenha uma função primordial:

Podemos afirmar, portanto, que a difusão da escolarização como categoria de atividade social foi fundamental para os processos de alteração da sociabilidade em curso, ao longo do século XIX e no início do século $\mathrm{XX}$, bem como para as mudanças dos mecanismos de produção das distinções sociais que significaram alterações expressivas nas relações de gênero, geração, etnia e classe social. (VEIGA, 2002, p. 99).

As bases para a produção de formas específicas de tratamento da criança em distinção ao mundo adulto tiveram na formação da família nuclear um considerável sustentáculo. Sob a égide da família nuclear, compondo-se do pai, um homem civilizado e honrado; da mãe, uma boa dona de casa e esposa; a criança seria educada ao projeto civilizatório da modernidade. As pulsões, a autodisciplina, o controle dos instintos e das emoções passam a ser comedidos na vida privada e na vida pública (ELIAS, 1994). Nesse sentido, a educação das mulheres começa a se erigir em manuais que valorizavam o trabalho doméstico, o amor ao lar, veiculando um padrão de como ser uma boa esposa, dona de casa e, por conseguinte, uma boa mãe. A casa passa a ser o lugar natural de destaque, sobretudo, da mulher burguesa. Já às mulheres mais pobres, os ofícios mais próximos dos cuidados da casa como o de costureiras e lavadeiras Ihes eram reservados. No Brasil, a partir do século XIX, também circulavam revistas e manuais que engendravam essa ideia: "[...] O objetivo principal era de que o privado fosse o educador do público com base na ação principal das mães de família. Nos bons princípios da educação materna no lar, estaria a garantia da multiplicação de homens e mulheres honrados e honestos, enfim civilizados" (VEIGA, 2004, p. 59).

Esse projeto de escolarização, ao longo dos séculos XIX e XX, foi se consolidando como 
democratização da escola para as massas. Paulatinamente, o acesso foi garantido a todos, tendo como uma das promessas a sonhada mobilidade social para as classes populares, a propagada "idade de ouro" da escola. De acordo com Narodowski (1999), a estabilização da escola só foi possível pela utilização de três estratégias: a contratação de docentes assalariados, a limitação da ação das igrejas e a obrigatoriedade escolar. O professor foi perdendo sua autonomia e a profissão passa a ser controlada, majoritariamente, pelo Estado.

A escolarização permitiu a continuidade do processo de civilização (ELIAS, 1994). O Estado assumiu a monopolização dos saberes pedagógicos e das técnicas de controle social, as quais a população não mais poderia utilizar. Restava, então, a internalização de uma produção de comportamento previsível, sobretudo a um setor da população cada vez mais visível, as crianças pobres. Essa previsibilidade se opunha à "falsa pedagogização", que fixava limites por meio de castigos físicos, por isso a necessária internalização dos processos de educação "[...] que devem se manifestar no interior do indivíduo, na descoberta de talentos, nas manifestações de potencialidades; enfim, que devem possibilitar a produção de previsibilidade" (VEIGA, 2002, p. 100). Ou seja, o modelo escolar foi idealizado para atingir a internalização dos processos educativos, buscando uma previsibilidade, facilitando a competição e a meritocracia. A seguir, serão vistas algumas homologias entre a formação escolar e as reformas das cidades, ambas constituidoras de um processo civilizatório e educativo.

Desse modo, para que houvesse uma dedicação maior ao trabalho por parte dos adultos, já que as crianças estavam na escola, ainda era necessário mudar a mentalidade das pessoas em relação a seus modos grosseiros e refiná-los ainda mais. Esse propósito, associou-se a reformas nas cidades e nos modos de viver nas cidades. Topalov, ao analisar o desenvolvimento urbano na Europa e na América do Norte, afirma que esse movimento se iniciou em 1880 e pretendia "mudar a cidade para mudar a sociedade e particularmente, o povo, essa era sua visão estratégica" (1996, p. 23).

O contexto europeu no início do século XX revelou, aos olhos de reformadores da época, como Beveridge, na Inglaterra, e Sellier, prefeito socialista de Paris, a necessária atuação do Estado para afastar os trabalhadores ocasionais, por exemplo, os estivadores da situação de trabalho intermitente (TOPALOV, 1996). O fato desse tipo de atividade laboral possibilitar trabalhar apenas dois ou três dias por semana, restando um tempo ocioso, passou a ser visto como, potencialmente, perigoso. As moradias insalubres dos cortiços que favoreciam a promiscuidade e a disseminação de doenças muito comuns na época, entre elas a tuberculose, poderiam colaborar para permanência desses trabalhadores na situação de trabalho ocasional. Desse modo, o trabalho assalariado, o seguro desemprego, assim como o tempo regulado para o descanso, foram se delineando nas políticas públicas.

Como em todas as reformas, a receptividade não foi uniforme. Havia um empecilho na consecução dessas ideias reformistas, o convencimento dos trabalhadores, pois esses não partilhavam das mesmas concepções de higiene, saúde e trabalho. A reforma nas cidades é imperiosa para a conquista desse intento, acompanhada de planeamento educativo visando ao convencimento progressivo de um melhor estilo de vida: 
Podemos ver, então, que duas políticas sociais progressistas (o seguro desemprego e a reforma da moradia) têm sua origememumprojetoeducativorelativoaostrabalhadoresurbanosenãonasexigênciasdestesúltimos.Essas políticassociais contrariavamdoishábitosbemarraigadosnasclassespopulares:amobilidadeeintermitênciado empregoassalariadoeapreferênciapelasmoradias baratasdeseusbairrostradicionais.(TOPALOV,1996,p.27).

Os desdobramentos pedagógicos advindos das considerações supracitadas podem ser circunscritos à imprescindível educação do homem para aquisição de melhores hábitos, uma vez que "[..] o progresso social exige uma mudança radical nos costumes dos operários, e essa mudança não depende apenas da moradia, mas, também, das condições globais da vida urbana" (TOPALOV, 1996, p. 26). Semelhantes processos ocorreram em reformas urbanas em todo o mundo ocidental. No Brasil, as associações entre reforma urbana e necessidade de transformação da população para uma cidade em mudança estiveram na agenda política da cidade do Rio de Janeiro no contexto da Reforma Pereira Passos ${ }^{4}$.

Veiga (2004) afirma que, desde o século XIX, as lógicas da modernidade influenciaram o modo de vida das pessoas nas principais nações europeias. Segundo Veiga,

Também no Brasil, as elites comungaram das mesmas ideias e apostaram na associação civilização e progresso. Embora desconheça o aparecimento do termo modernidade no Brasil, é certo que o termo moderno pode ser encontrado dicionarizado na língua portuguesa em 1789 e no mesmo dicionário, edição de 1844 , tem-se o registro das palavras moderníssimo e modernista. Por sua vez, diferentes autores brasileiros contemporâneos fazem referência à modernidade nacional a partir do século XIX, em associação às transformações materiais e de costumes ocorridos no país [...]. (2004, p. 36).

Portanto, a relação causal entre desenvolvimento e progresso pode levar à falsa compreensão de atraso comparando com os países europeus. A cristianização dos costumes e o fortalecimento da vida privada das famílias também ocorreram no Brasil em maior ou menor escala, de acordo com as suas características peculiares. Por ter sido um país escravocrata, a invenção da infância, da vida privada e da escolarização tomou contornos próprios e diferentes singularidades, "[...] a ênfase da escolarização não se fez na busca de completar um processo de civilização já em curso, mas de estabelecer as civilidades e, principalmente, legitimar e dar visibilidade a uma nova configuração de poder em construção" (VEIGA, 2002, p.101).

Os estudos realizados por Del Priore (2010) acerca da infância no contexto brasileiro indicam que as marcas do escravismo deixaram um legado de uma injusta distribuição de riqueza e de oportunidades na nossa sociedade. Mostra-se paradoxal o fato de mulheres negras forras terem escravos, às vezes, seus meios irmãos. Também o fato de crianças brancas possuírem escravos. Apesar da abolição da escravatura, crianças e adolescentes continuaram nas senzalas trabalhando nos canaviais. Com o desenvolvimento das cidades, a proliferação de cortiços e favelas, a partir dos séculos XIX e XX, essas crianças e adolescentes foram considerados os dejetos da sociedade e denominados pejorativamente de pivetes, gatunos. O trabalho infantil era destacado com uma alternativa salvacionista dos supostos perigos e malefícios da rua e da pobreza e não, necessariamente, a escola. De acordo com Kuhlmann Jr. (2004), na primeira metade do século XIX surgem em vários países do continente europeu, e especificamente no Brasil na década de 1870, as primeiras instituições dedicadas à educação da criança pequena, como iniciativas reguladoras da vida social, 
dada a crescente industrialização e urbanização. Essas instituições eram vistas como a vanguarda da civilização e do progresso

A 'proteção à infância' é o novo motor que impulsiona a criação de uma série de associações e instituições para cuidar da criança sob diferentes aspectos: da sua saúde e sobrevivência - com os ambulatórios obstétricos e pediátricos; dos seus direitos sociais - com as propostas de legislação e de associações de assistência; da sua educação e instrução - com o reconhecimento de que estas possam ocorrer desde o nascimento, tanto no ambiente privado como no espaço público. (KUHLMANN JR., 2004, p. 473).

A partir do escopo teórico apresentado, pode-se inferir que os processos de escolarização e a intencionalidade do desenvolvimento de determinados projetos nas cidades visaram à produção de civilidades alinhadas à modernização. Nesse sentido, a institucionalização da infância por intermédio da escola foi a tônica desse processo, chegando nos dias atuais à universalização escolar. A escola, nos moldes como foi organizada, contando com agrupamentos de estudantes por faixa etária, divididos por níveis de conhecimento, acompanhados pela maestria de um único professor, considerado mais experiente e capacitado, acompanha a todos até hoje.

Ao refletir sobre a condição da instituição escolar na contemporaneidade, Fernandez-Enguita (2016) indaga-se quanto ao fato de a escola ainda sobreviver quase incólume, apesar das inúmeras transformações no mundo do trabalho e na sociedade. O sociólogo espanhol enfatiza, como pretensa resposta, a questão da obrigatoriedade escolar, uma vez que não há outra instituição que a substitua. Além disso, a custódia da infância é feita por uma instituição de massa muito barata. A escola é um direito, mas também uma obrigação, uma imposição. Portanto, continua sendo a única instituição educativa em larga escala para crianças e adolescentes.

\section{Cidadania, Infância e Cidade}

A reflexão desenvolvida na seção anterior permite vislumbrar a forma peculiar por meio da qual a modernidade produziu a infância e a escolarização, através de diferenciações fortemente marcadas entre o público e o privado, a criança e o adulto. Essas diferenciações foram vinculando a criança ao mundo privado, à dependência, à passividade, contrapondo-se às possibilidades do adulto, visto como alguém com direito à vida pública, à independência, à atividade (MÜLLER, 2012). Essa visão corroborou na identificação da interação com a cidade, dadas suas características, como sendo mais propícia ao adulto. Desse modo, as crianças foram sendo segregadas ao mundo privado da casa, da escola, dos parques e outros espaços planejados especificamente para a infância. De igual maneira, também ficou alheia ao planejamento urbano e quase sem o consentimento de usufruir do espaço da rua de maneira mais autônoma, ainda que, na contemporaneidade, à criança seja outorgado o reconhecimento de sujeito de direitos.

Na Constituição Federal de 1988, a educação é apresentada como direito público subjetivo e expande à faixa etária de 0 a 6 anos, que anteriormente não estava contemplada. Outro importante advento que estabelece o reconhecimento da criança e do adolescente como sujeitos privilegiados e prioritários no atendimento aos direitos sociais é a aprovação do Estatuto da Criança e do Adolescente pela Lei 8069/90. A LDB 9394/96 consegue avançar 
nas conquistas à educação para as crianças e adolescentes, considerando a Educação Infantil, Ensino Fundamental e Ensino Médio etapas da Educação Básica. Mais recentemente, a Emenda Constitucional 59/09 ampliou a faixa da educação escolar obrigatória para as crianças de quatro anos aos jovens de dezessete anos.

Nesse breve retrospecto, a partir de alguns marcos legais, percebe-se um avanço da deferência à criança e aos jovens na legislação brasileira. Aliado a esses instrumentos legais, a vanguarda do pensamento pedagógico acerca da infância trouxe importantes contribuições advindas de diferentes campos teóricos, propiciando a compreensão das crianças como sujeitos produtoras de cultura. No trabalho de Sirota (2001), ao analisar a emergência da noção do "ofício de criança", tomando-a como objeto sociológico no âmbito da sociologia da educação, o autor acompanhou a evolução da literatura pedagógica na tradição francesa, identificando pontos de interseção com a de língua inglesa, as quais se coadunam ao ratificar: "As crianças devem ser consideradas como atores em sentido pleno e não simplesmente como seres em devir. As crianças são ao mesmo tempo produtos e atores dos processos sociais" (SIROTA, 2001, p. 19). Pode-se destacar, ainda, Montandon (2001, p. 51), ao realizar um balanço das pesquisas sociológicas em língua inglesa a respeito da infância, que também destaca o sentido de "as crianças são e devem ser estudadas como atores na construção de sua vida social e da vida daqueles que as rodeiam. Os métodos etnográficos são particularmente úteis para o estudo da infância".

Ao examinar as pesquisas realizadas no Brasil sobre a produção do tema infância e educação, Quinteiro (2002) destaca que se trata de um campo em construção, contudo desde a década de 1940 parece emergir os primórdios de uma compreensão diferenciada em relação à criança. Essa autora distingue o clássico trabalho etnográfico de Florestan Fernandes com um grupo de crianças residentes em bairro operário da cidade de São Paulo, o qual buscou entender "[...] a criança como participante ativo da vida social" (QUINTEIRO, 2002, p.30).

A discussão cingida, anteriormente, procurou mostrar o deslocamento na legislação educacional e no pensamento pedagógico, da visão de criança passiva ao de protagonista, podendo ser objeto privilegiado da sociologia da educação, questão essa muito cara aos estudos da infância. A aproximação das temáticas infância e cidade são possibilitadas quando se dão a partir de um reconhecimento "[...] da ruptura da associação da infância com uma etapa passiva, de incompletude e de total dependência. Logo, analisar como a criança entende a cidade envolve discutir vários conceitos, sobretudo o de infância" (MÜLLER, 2012, p. 296).

Em defesa de um possível desenvolvimento de um novo campo de estudo, infância e cidade, Müller e Nunes (2014) reiteram a necessária importância do rompimento de binarismos que forjam dicotomias entre o mundo adulto e infantil, vida privada e vida pública, autonomia e dependência, alertando para:

A concepção de criança como um ser incapaz, passivo e completamente dependente é maximizada quando deslocamos o nosso olhar para o contexto da vida pública, para o espaço da cidade. Isto pode ser tanto observado na própria tradição sociológica bem como no mundo social, principalmente no comportamento dos adultos em relação à criança nos médios e grandes centros urbanos. (MÜLLER; NUNES, 2014, p. 661). 
Nesse sentido, considerar a criança como participante ativo social na plenitude do exercício de sua cidadania é condição fundamental para o desenvolvimento do campo de estudos, infância e cidade. As reformas nas cidades, como já se viu, visavam à produção do homem civilizado. Ser civilizado é condição de cidadania. O conceito de cidadania, de acordo com Dubet (2011, p.289), é um dos temas mais intrigantes em virtude de seu caráter paradoxal, pois "implica a igualdade e a autonomia dos sujeitos, enquanto a educação repousa sobre a desigualdade fundamental dos mestres e dos alunos, dos adultos e das crianças".

A formação de cidadania é prioritariamente realizada durante a infância para que, na fase adulta, o sujeito atue competentemente na sociedade e, por conseguinte, na cidade. A criança é preparada por meio de programas institucionais para, no futuro, durante a adultez, intervir como cidadã no mundo. Mesmo que a criança seja entendida como cidadã com garantias legais de seus direitos, como já se viu anteriormente, a infância é considerada um momento preparatório e isso reflete na eventual viabilidade de sua intervenção na cidade. Assim sendo, Müller (2012, p. 298) argumenta que "criança, infância e cidade constituem um tema de pesquisa emergente, que demanda um referencial teórico interdisciplinar. Concebendo não somente as crianças, mas todos os grupos geracionais, como seres ativos, criativos e em permanente formação [...]".

O palco para a consecução da construção do sujeito de direitos, o chamado cidadão, teve sua pujança no desenvolvimento das cidades. Veiga (2007) afirma que, na cidade, materializouse a criatividade humana para vencer a natureza, assim como foi o espaço privilegiado da disseminação de escolas, de templos e monumentos que perpetuaram ideias e valores, o lugar da produção da autonomia, da liberdade e do indivíduo. Em finais dos séculos XVIII e XIX, as cidades eram aglomerados de pessoas que necessitavam de deslocamento para possibilitar uma maior organização da população "[...] Mendigos, negros, loucos, prostitutas, rebeldes tornaram-se um estorvo para o progresso e a almejada civilidade [...]", de acordo com Veiga (2007, p. 400), uma nova civilização estava em marcha cuja preocupação era intervir no meio em que viviam.

Ao redor do mundo e também no Brasil, reformas em grandes cidades, como Rio de Janeiro, Vitória, Recife, Porto Alegre e Belo Horizonte foram implantadas com a finalidade de evitar um suposto contágio tanto de doenças físicas como de hábitos grosseiros. Esses empreendimentos buscavam facilitar o deslocamento para o trabalho e também precisavam desenvolver um culto à pátria, um gosto particular pela nação, bem como da ordem e do progresso. O objetivo seria a inserção das cidades e, por conseguinte, do indivíduo na lógica da modernidade, buscando a resposta para o que seria um cidadão. Sendo assim, "As reformas dos espaços estiveram carregadas de pressupostos pedagógicos; a referência à necessidade de educação sob todos os aspectos é constante nos mais diferenciados discursos e práticas [...]" (VEIGA, 2007, p. 403).

A constituição da cidadania passava pela reestruturação das cidades, da educação e refinamento do gosto das pessoas e dos seus modos de higiene. A população necessitava ser educada com a finalidade de obediência, buscando a unidade nacional desejada pela república brasileira. Para tal, a escola necessitava ser orientada em função de determinados conteúdos com ênfase na formação da cidadania direcionada aos interesses da nação: "[...] A educação tornou-se um símbolo integrado à república pela crença na sua capacidade de regenerar, moralizar, disciplinar e unificar as diferenças" 
(VEIGA, 2007, p. 404). O hino, a bandeira, o modelo de família nuclear, os hábitos de higiene com a casa e com o corpo, as unidades didáticas de estudo voltados para o bairro, o município e o estado, foram marcas indeléveis dessa época.

Essa reestruturação nas cidades ocorrida sobretudo durante o século XX, em grandes cidades, não foi devidamente planejada e organizada por urbanistas, conforme estudos de Lansky, Gouvêa e Gomes (2014), Nunes (2007), Müller e Nunes (2014). As reformas urbanas sonegaram as classes trabalhadoras, empurrando-as para a periferia das cidades, segregando formas de lazer e de socialização, delimitando espaços privados de recreação como shoppings, condomínios fechados destinados às classes médias e altas. Mormente, as periferias das cidades, na atualidade, são percebidas como altamente perigosas e a circulação das pessoas que vivem em tais bairros são vedadas de forma velada nos locais mais privilegiados da cidade.

Cada vez mais a convivência humana se dá em lugares devidamente planejados. A principal justificativa para tal é a desordem urbana, altos índices de violência, falta de segurança nas ruas. Desse modo, a presença das crianças nas cidades é facultada a lugares que aparentam certa segurança "Por deterem um discurso de proteção às crianças, os adultos facilmente as excluem da cidade, restringindo as interações de ambos ao espaço privado ou a lugares previamente demarcados no espaço público." (MÜLLER; NUNES, 2014, p. 670).

A organização das cidades denota uma intervenção basicamente adulta, sendo pensada pelos adultos e para eles. Tonucci (2016), recuperando a metáfora que abre o presente ensaio, acentua essa problemática ao afirmar que as metrópoles, na contemporaneidade, são planejadas para os carros e não para as pessoas. A via pública se destina ao comércio; a circulação dos meios de transporte buscando facilitar, sobretudo, o acesso ao trabalho. O lazer e o espaço das interações infantis são posicionados em lugares específicos como praças, parques e creches (LANSKY; GOUVÊA; GOMES, 2014; MÜLLER; NUNES, 2014) com finalidade lúdica a partir de um gosto estético infantilizado dentro dos limites de uma visão adultocêntrica. A circulação das crianças pelas cidades é mediada pelos adultos que, ao considerarem a rua muito perigosa, cada vez mais se confinam em lugares fechados e aparentemente mais seguros. Nesse sentido, Muller (2012, p.298) afirma que:

As crianças apresentam preocupações, sugestões e medos, o que evidencia a necessidade de serem ouvidas e de participarem das discussões sobre a cidade em que vivem. O planejamento das cidades é feito com base em diferentes conceitos sobre os seus habitantes e, aparentemente, crianças não têm direito pleno à participação, pois são consideradas menos capazes [...].

O espaço das cidades é entendido como potência educadora em projetos como o das cidades educadoras, conceito subjacente ao Programa Mais Educação, como argumentamos no início deste trabalho. A cidadania é forjada em diferentes programas educativos desenvolvidos nas cidades, contudo as cidades são pensadas a partir do olhar do adulto e para suas próprias necessidades, assim como os espaços destinados às crianças também são planejados de acordo com tal propósito.

Apesar de as crianças terem seus direitos garantidos, sua falta de participação no planejamento urbanoainda demonstraumentendimento dequeo pensamento adulto sobrepuja 
o infantil. Ouvi-las nos mais diferentes aspectos ainda parece estar longe de realmente ser uma conquista de fato. As crianças estão protegidas dos supostos malefícios da rua, interagindo em espaços especializados e fortemente mediados pelos adultos, diminuindo as potencialidades de socialização. "Precisamos atentar, contudo, para a naturalização de uma relação de poder, que associa de forma imperativa o uso do espaço urbano quase exclusivamente ao adulto [...]" (MÜLLER; NUNES, 2014, p. 670). Olhar as cidades desde o prisma apresentado nesse trabalho convém se refletir sobre a pretensa competência da cidade em se converter em diferentes qualidades educativas, tal qual exaltado em programas governamentais hodiernos.

\section{CONSIDERAÇõES FINAIS}

Diversos estudiosos contemporâneos, dentre estes Tonucci (2016), Lansky, Gouvêa e Gomes (2014), Müller (2012), Müller e Nunes (2014), ainda que díspares entre si, têm afirmado que a cidade deve assumir a responsabilidade de acolher as crianças visando à autonomia de seus deslocamentos, oportunizando o encontro com o outro, com o reconhecimento de outros modos de ser e de viver. A participação política das crianças, viabilizada pela escuta apurada a respeito das cidades em que habitam, parece ser um caminho exitoso para torná-las de fato cidades educadoras. Os processos de participação, considerados condição de cidadania, não podem desconsiderar a politicidade produzida por determinados segmentos da sociedade. As crianças têm percepções acerca da realidade, são atores capazes de interpretar o seu entorno e transformá-lo. Portanto, para que uma cidade seja definida como educadora ou para que se assumam suas efetivas potencialidades pedagógicas, faz-se necessário se converterem as crianças ao centro desse debate, não como meros atores em processo de civilização, mas como protagonistas de seu tempo e de um tempo melhor, no futuro.

\section{REFERÊNCIAS}

ALGEBAILE, E.; RISSATO, D. Indicações históricas e conceituais para a análise das políticas de escolarização em curso no Brasil. Quaestio, v. 17, n. 2, p. 315-331, nov. 2015.

ARIÈS, P. História social da criança e da família. Rio de Janeiro: LTC, 1981.

BENJAMIN, W. Reflexões sobre a criança, o brinquedo e a educação. São Paulo: Duas Cidades. 2002.

CANÁRIO, R. A escola: das “promessas” às “incertezas”. Educação Unisinos, v.12, n.2, p.73-81, 2008.

CAVALIERE, A. M. Escola pública de tempo integral no Brasil: filantropia ou política de Estado? Educação e Sociedade, v. 35, n. 129, p. 1205-1222, out-dez, 2014.

COELHO, L. M. C. da C. Integração escola-território: "saúde" ou "doença" das instituições escolares? In: MAURÍCIO, L. V. (Org.) Tempos e espaços escolares: experiências políticas e debates no Brasil e no mundo. Rio de Janeiro: FAPERJ, 2014. p.181-198 
DEL-PRIORE, M. (Org.) História das crianças no Brasil. São Paulo: Contexto, 2010.

DIAZ-VILLA, M. Escolarizacion y sociedade en el contexto latinoamericano. Quaestio, Sorocaba, São Paulo, v.17, n. 2, p. 299-314, nov. 2015.

DUBET, F. Mutações cruzadas: a cidadania e a escola. Revista Brasileira de Educação, v. 16, n. 47, maio-ago. 2011.

ELIAS, N. O processo civilizador: uma história dos costumes. Rio de Janeiro: Jorge Zahar, 1994.

ENGUITA, M. F. La educacion en la encrucijada. Madrid: Fundacion Santillana, 2016.

GADOTTI, M. A escola na cidade que educa. Cadernos CENPEC, v.1, n.1, 2006.

GALEANO, E. Espelhos: uma história quase universal. Porto Alegre: L\&PM, 2008.

GORELIK, A. O moderno em debate: cidade, modernidade, modernização. In: MIRANDA, W. M. (Org.)

Narrativas da Modernidade. Belo Horizonte: Autêntica, 1999. p.55-80

KUHLMANN JR, M. Educando a infância brasileira. In: FARIA FILHO, L. M. (Org.) A infância e sua educação: materiais, práticas e representações [Portugal e Brasil]. Belo Horizonte: Autêntica, 2004. p.469-496

LANSKY, S.; GOUVÊA, M. C. S. de; GOMES, A. M. R. Cartografia das infâncias em região de fronteira em Belo Horizonte. Educação e Sociedade. Campinas, v. 35, n. 128, p.629-996, jul./set., 2014

MARTÍN-BARBERO, J. Projetos de modernidade na América Latina. In: DOMINGUES, J. M.;

MANEIRO, M. América Latina hoje: conceitos e interpretações. Rio de Janeiro: Civilização Brasileira, 2006. p.20-49

MINISTÉRIO DA EDUCAÇÃO (MEC). Secretaria da Educação Continuada, Alfabetização e Diversidade (SECAD). Programa Mais Educação. Passo a passo. Brasília, 2015.

MOLL, J. A agenda da educação integral: compromissos para sua consolidação como política pública. In: MOLL, J. et al. Caminhos da educação integral no Brasil: direito a outros tempos e espaços educativos. Porto Alegre: Penso, 2012.

MONTANDON, C. Sociologia da infância: balanço dos trabalhos em língua inglesa. Cadernos de Pesquisa. São Paulo, n.112, p. 33-60, mar/2001.

MÜLLER, F. Infâncias e cidades: Porto Alegre através das lentes das crianças. Educação e Realidade. Porto Alegre: v. 37, n. 1, p. 295-318, jan./abr., 2012.

MÜLLER, F.; NUNES, B. F. Infância e cidade: um campo de estudo em desenvolvimento. Educação e Sociedade. Campinas: v. 35, nº. 128, p. 629-996, jul.-set., 2014.

NARODOWSKI, M. Después de classe: Desencantos y desafíos de la escuela actual. Buenos Aires: Ediciones Novedades Educativas, 1999.

NUNES, C. (Des)encamentos da modernidade pedagógica. In: In: LOPES, E.M.; FARIA FILHO, L. M., VEIGA, C.G. (Orgs.). 500 anos de educação no Brasil. Belo Horizonte: Autêntica, 2007. p.370-398

QUINTEIRO, J. Infância e educação no Brasil: um campo de estudos em construção. In: FARIA, A. L. G.; DEMARTINI, Z. B. F.; PRADO, P. D. (Orgs.). Por uma cultura da infância: metodologia de pesquisa com crianças. Campinas, Autores Associados, 2002. p. 19-48

SANTOS, C. N. F. dos; VOGEL, A. (Coord.). Quando a rua vira casa: a apropriação de espaços urbanos de uso coletivo em um centro de bairro. São Paulo: Projeto, 1985. 
SARMENTO, M. J. Gerações e alteridade: interrogações a partir da sociologia da infância. Educação e Sociedade. Campinas, vol. 26, n. 91, p. 361-378, maio/ago, 2005.

SIROTA, R. Emergência de uma sociologia da infância: evolução do objeto e do olhar. Cadernos de Pesquisa. São Paulo, n.112, p. 7-31, mar/2001.

TONUCCI, F. Com os olhos de criança. Porto Alegre: Artmed, 2003. p.160

TONUCCI, F. A criança como paradigma de uma cidade para todos: entrevista. 21/09/2016. Disponível em: http://cidadeseducadoras.org.br/reportagens/francesco-tonucci-a-crianca-como-paradigma-de-uma-cidadepara-todos. Entrevista concedida a Raiana Ribeiro.

TOPALOV, C. Da questão social aos problemas urbanos: os reformadores e a população das metrópoles em princípios do século XX. RIBEIRO, L.C. Q., PECHMAN, R. (Org.). Cidade, povo e nação. Rio de Janeiro: Civilização Brasileira, 1996. p.23-51

VEIGA, C. G. A escolarização como projeto de civilização. Revista Brasileira de Educação. Rio de Janeiro, n. 21, p. 90-103 set-dez/2002.

. Infância e modernidade: ações, saberes e sujeito. In: FARIA FILHO, L. M. (Org.). A infância e sua educação: materiais, práticas e representações [Portugal e Brasil]. Belo Horizonte: Autêntica, 2004. p.35-82

. A educação estética para o povo. In: LOPES, E. M.; FARIA FILHO, L. M.; VEIGA, C. G. (Orgs.). 500 anos de educação no Brasil. Belo Horizonte: Autêntica, 2007. p.399-422

Artigo recebido em: 16/04/2017

Aprovado em: 02/08/2017

Contato para correspondência:

Rodrigo Manoel Dias da Silva.E-mail: rodrigoddsilva@hotmail.com

NOTAS

1 Projeto internacional coordenado pelo italiano Francesco Tonucci, de acordo com o Observatório do PNE. Visa por meio da participação das crianças tornar o espaço urbano mais humano e propício à formação de cidadania.

2 Elaborado no bojo do Plano de Desenvolvimento da Educação (PDE) por meio de Portaria Interministerial. O Programa Mais Educação objetiva induzir a educação em tempo integral, contando com o apoio de oficinas realizadas no contraturno escolar. Tais oficinas são elaboradas visando ao debate dos saberes e das práticas contemporâneos com os espaços potencialmente educacionais da comunidade e da cidade (MEC, 2015).

3 De acordo com revisão bibliográfica específica a respeito do tema, o conceito de cidade educativa foi cunhado em 1970 (Ano Internacional da Educação) pela UNESCO. Em 1990, na cidade de Barcelona, ocorreu o Primeiro Congresso Internacional das Cidades Educadoras sendo aprovada uma carta de princípios básicos constituintes do perfil de uma cidade educadora. Nas palavras de Gadotti (2006) uma cidade pode ser considerada educadora quando além de suas funções tradicionais exerce a função de formar para e pela cidadania, promovendo e desenvolvendo o protagonismo de todos: crianças, jovens, adultos e idosos.

4 Reforma política promovida pelo prefeito Pereira Passos, na cidade do Rio de Janeiro, no começo do século XX. 